\title{
Bigger isn't always better: body size, developmental and parental temperature and male territorial success in Drosophila melanogaster
}

\author{
KELLY R. ZAMUDIO, RAYMOND B. HUEY \& WAYNE D. CRILL* \\ Department of Zoology NJ-15, University of Washington, Seattle, WA 98195, U.S.A.
}

(Received 10 November 1993; initial acceptance 4 February 1994;

final acceptance 7 March 1994; MS. number: A6854)

\begin{abstract}
The effect of developmental temperature $\left(18^{\circ} \mathrm{C}\right.$ versus $\left.25^{\circ} \mathrm{C}\right)$ on the body size and territorial success of male fruit flies, Drosophila melanogaster, in paired contests was examined. When tested at ambient temperatures of either $18^{\circ} \mathrm{C}$ or at $27^{\circ} \mathrm{C}$, adult males raised at $25^{\circ} \mathrm{C}$ were relatively small in size but nevertheless had greater territorial success (control of a food/oviposition resource) than males raised at $18^{\circ} \mathrm{C}$. This result negates a 'size-advantage hypothesis', which predicts that males raised at $18^{\circ} \mathrm{C}$ should be more successful at either contest temperature by virtue of their larger size. It also negates an 'acclimation-advantage hypothesis', which predicts that males raised at $18^{\circ} \mathrm{C}$ should be more successful than males raised at $25^{\circ} \mathrm{C}$ in contests at $18^{\circ} \mathrm{C}$, but less successful at $27^{\circ} \mathrm{C}$. The data are consistent, however, with an 'optimal developmental temperature hypothesis', which suggests that flies raised at $25^{\circ} \mathrm{C}$, even though phenotypically small, are physiologically vigorous and will perform relatively well under diverse environmental circumstances. Thus, bigger isn't always better. In a small-scale experiment (territoriality scored only at $\left.27^{\circ} \mathrm{C}\right)$ in which all males had the same developmental temperature $\left(25^{\circ} \mathrm{C}\right.$ ) males whose parents developed at $25^{\circ} \mathrm{C}$ were more successful than were males whose parents developed at $18^{\circ} \mathrm{C}$. These experiments demonstrate that developmental temperatures, both within and between generations, influence territorial success in male flies.
\end{abstract}

Body size has a major impact on reproductive success and fitness (Roff 1981; Barbault 1988). In both field and laboratory studies with several species of Drosophila, for example, large males typically dominate small males at oviposition sites, thereby gaining a substantial mating advantage (Ewing 1964; Partridge \& Farquhar 1983; Hoffmann 1987a, b, 1988; Partridge et al. 1987; Wilkinson 1987; Markow 1988; Santos et al. 1988; but see Boake 1989; Hoffmann \& Cacoyianni 1990; Markow \& Sawka 1992). The size of a male is strongly influenced not only by its genes, but also by environmental conditions (e.g. larval density, nutrition, temperature) it experienced during development (Robertson 1963; David et a!. 1983; Cavicchi et al. 1985; Hillesheim \& Stearns 1991). For example, males raised at low temperature are phenotypically larger than males raised at high temperature (David et al. 1983; Scheiner \& Lyman 1989). Consequently, the temperature at which a male fly develops might have a major impact on its territorial success as an adult.

\footnotetext{
*Present address: Department of Zoology, University of Texas, Austin, TX 78712, U.S.A.
}

Here we report experiments that involve manipulating the developmental (and parental) temperature of male flies (D. melanogaster) and then examining the consequences on body size and on territorial success. Territorial success is an important behavioural variable that can influence a male fly's feeding success (A. A. Hoffmann, personal communication) as well as his mating success (Dow \& von Schilcher 1975; Hoffmann 1988; but see Partridge et al. 1987; Markow 1988; Hoffmann \& Cacoyianni 1990). Our experiments were originally designed to discriminate between two hypotheses (not necessarily exclusive) concerning the effects of developmental temperature on territorial success. If large size in fact determines male dominance ('size-advantage hypothesis'; Huey et al. 1995), then males raised at low temperature (thus large) should be more successful than males raised at high temperature. Moreover, males raised at low temperatures should be more successful in contests at either high or low ambient temperatures. Alternatively, if development at one temperature later enhances performance of an adult at that same temperature ('acclimation-advantage hypothesis'; Leroi et al. 
1994; Huey et al. 1995), then a male raised at high temperature (thus small) will be more successful than a male raised at low temperature (thus large) only if both are tested at a high ambient temperature. Thus this second hypothesis proposes that the physiological advantage (at least with respect to territorial success) of acclimatization to a particular thermal environment outweighs size advantages of development at low temperature. Surprisingly, our data contradict both hypotheses. In paired contests at low or high temperature, males raised at high temperature (thus small) were usually dominant over males raised at low temperature. Interestingly, males whose parents were raised at high temperature were usually dominant over males whose parents were raised at low temperature. Thus, the temperature during development, both within and between generations, has a profound effect on adult vigour as well as on size (Crill 1991), with the result that bigger isn't always better.

\section{METHODS}

Populations of D. melanogaster were founded from a large outbred stock (collected in Brighton, U.K. in 1984) and maintained thereafter at $25^{\circ} \mathrm{C}$ (Huey et al. 1991). From 1984 until summer 1991, the flies were raised with overlapping generations in a large population cage (no control over adult or larval density) with 12 media bottles that were rotated on a 4-week schedule (see Huey et al. 1991). From summer 1991 until December 1991 (when the present experiments were conducted), flies were raised at low density (ca 50 eggs/vial; corn meal, molasses, agar, yeast, tegosept) with non-overlapping generations (ca 500 flies/ generation).

Experimental flies were raised from egg to adult at $18^{\circ} \mathrm{C}$ ('low-temperature males') or $25^{\circ} \mathrm{C}$ ('hightemperature males'). These developmental temperatures are well within the range experienced by flies in nature (Jones et al. 1987) and thus are ecologically relevant. Shortly after eclosion, males were briefly immobilized by chilling and marked on the top of the thorax with a tiny spot of red or white acrylic paint (Hoffmann 1987a). Colour was randomized across developmental temperature treatments. (Colour had no effect on dominance, see below.) Males were then isolated and maintained at their developmental temperature until testing. To correct for the accelerating effects of high temperature on 'physiological age' (Long et al. 1980; Taylor 1981), we tested hightemperature males at an age of 3-4 days but low-temperature males at 6-7 days old. These ages were scaled to observed differences in development time in these lines. In any case, Hoffmann (1990) found that territorial success did not differ between 3- and 7-day-old males, even though territorial success of 1-day-old males was relatively low.

Territorial success was tested (modified from Hoffmann 1987a, b) after gently aspirating pairs of male flies (a high-temperature and a lowtemperature male) into clear cylindrical cages $(100 \mathrm{~mm}$ diameter, $40 \mathrm{~mm}$ high) with a disc of medium $(20 \mathrm{~mm}$ diameter, $10 \mathrm{~mm}$ high, covered with a thin suspension of yeast paste) resting on a moistened tissue substrate. A mated female was immediately added to increase male territoriality (Hoffmann \& Cacoyianni 1990). The disc of medium, which represents both food and a potential oviposition site (Markow 1988), served as a defendable resource (Hoffmann 1987a, b). Moreover, because mating in $D$. melanogaster occurs at the oviposition site (Markow 1988) and because such sites are patchily distributed in nature (Atkinson \& Shorrocks 1977), a male that dominates the food disc should generally have high mating success (Dow \& von Schilcher 1975; Hoffmann 1988).

Territorial success was tested at either 18 or $27^{\circ} \mathrm{C}$. Males were given $2.5 \mathrm{~h}$ to establish territorial patterns (Hoffmann 1987a, b), and then we began scoring territorial success during spot censuses at $0 \cdot 5$-h intervals over the next $6 \mathrm{~h}(12$ observations/pair). During each spot census we observed the males for $10 \mathrm{~s}$ and recorded which male(s) occupied the food/oviposition resource. If only one male occupied the oviposition site during all or part of the census, that male was designated as successful. If both males (or no male) were present during the census, we waited $40 \mathrm{~s}$ and then re-inspected the arena. If both males remained (or if no male was on the oviposition site), no male was designated as successful. After 12 spot censuses, we scored overall territorial success in two ways. First, we gave each male a numerical score based on the total number of censuses (range= $0-12$ ) at which it alone had dominated the oviposition/food site. Second, we also assigned overall territorial success (categorical scale) to one 
male if it alone occupied the food/oviposition site in at least two-thirds of all trials in which one male occupied the territory. Using this criterion we assigned territorial success in 27 of 38 pairs tested at $27^{\circ} \mathrm{C}$ and in 26 of 39 pairs at $18^{\circ} \mathrm{C}$. The probability of making a territorial assignment was unaffected by test temperature $\left(\chi^{2}\right.$ test: $\left.P=0.74\right)$ or by the difference in body mass of the flies (ANOVA: $P=0.92$ ). Territorial success was not influenced by the colour of the paint spot $(P>0 \cdot 3)$. Flies were scored 'blind' with respect to developmental temperature, and a given male was used in only one trial. At the completion of the trials, all flies were removed, dried, and weighed on a microbalance.

An independent experiment demonstrates that our census technique, which directly scores only relative occupancy of the food/oviposition site, adequately indexes territorial success. We continuously followed focal pairs $(N=9)$ in the above arenas for $1.5 \mathrm{~h}$, and we recorded the cumulative time each male spent on the oviposition site and the number of chases (a dominance behaviour that correlates with overall dominance; see Hoffmann 1987a) by each male. Immediately thereafter, we conducted spot censuses (as above) of these pairs for an additional $6 \mathrm{~h}$. In eight of nine trials, a definite winner (categorical criteria above) was assigned using data from the spotcensus technique. In seven of these eight cases, the winner was also that male that spent more time on the food patch during the prior focal-pair observation period $(P=0.035)$. For seven pairs, we also recorded the number of chases by each fly. Males assigned as successful based on their occupancy scores made significantly more chases per trial than did males assigned as unsuccessful (successful males $=8 \cdot 1 \pm 3 \cdot 91$, unsuccessful males $=0.3 \pm 0 \cdot 18$; Wilcoxon matched-pairs signed-ranks test: $P=0.046$ ). Thus relative occupancy of the food/oviposition site is an adequate proxy for direct observation of territorial success.

We conducted an additional, but small-scale $(N=16$ pairs) experiment to test the possible effects of parental temperature on offspring territorial success. Parental temperature influences heat tolerance and adult body size in these flies (Crill 1991); and parental effects are often important in insects (Mousseau \& Dingle 1991). We raised parental flies (egg to adult) at either 18 or $25^{\circ} \mathrm{C}$, collected their eggs and raised them (egg to adult) at a common temperature of $25^{\circ} \mathrm{C}$, and then tested males whose parents were both raised at $18^{\circ} \mathrm{C}$ against males whose parents had been raised at $25^{\circ} \mathrm{C}$. These tests were run only at an ambient temperature of $27^{\circ} \mathrm{C}$.

Statistical analyses of territorial data are complicated by the non-independence of behavioural scores of individuals in a pair. To circumvent this problem, we developed two approaches. First, to determine whether developmental temperature influenced territoriality within a given test temperature, we used Wilcoxon matched-pairs signedranks tests, which evaluate the difference in territorial scores of paired individuals rather than the individual scores. Second, to consider simultaneously the effects of developmental temperature, test temperature, and body mass, we developed a general linear model of the following form

$$
Y=a+T_{\text {test }}+\Delta_{\text {mass }}+\left(T_{\text {test }}\right)\left(\Delta_{\text {mass }}\right)
$$

where the dependent variable $Y$ is the difference in territorial scores (specifically, score for the $25^{\circ} \mathrm{C}$ male minus score for the $18^{\circ} \mathrm{C}$ male), $a$ is the intercept or grand mean, $T_{\text {test }}$ is the test temperature, $\Delta_{\text {mass }}$ is the difference in dry body mass between the males (that is, mass $_{25}-$ mass $_{18}$ ) and $\left(T_{\text {test }}\right)\left(\Delta_{\text {mass }}\right)$ is the interaction between test temperature and the difference in dry body mass (error term not shown). A significant and positive intercept would indicate that males reared at $25^{\circ} \mathrm{C}$ have a territorial advantage independent of test temperature and the difference in body mass. (Significance of the remaining terms is selfexplanatory.)

\section{RESULTS}

\section{Developmental Temperature, Body Size and Territorial Success}

Developmental temperature had a significant effect on adult male size. Males that developed at low temperature were heavier on average (by $9.4 \%$ ) in dry body mass (Wilcoxon matched-pairs signed-ranks test: $N=77$ pairs, $P<0.001$ ) than were males that developed at high temperature ( $\bar{X}=0.267 \pm 0.003 \mathrm{mg}$ versus $0.244 \pm 0.003 \mathrm{mg}$, respectively). Furthermore in $76.7 \%$ of all pairs, the heavier male had developed at low temperature.

Developmental temperature also affected male territorial success. We initially examined these 
Table I. Mean ( $\pm \mathrm{SE}$ ) territorial scores (number of censuses at which a given male alone occupied the food/oviposition site) of $D$. melanogaster males raised at $18^{\circ} \mathrm{C}$ or at $25^{\circ} \mathrm{C}$ and then tested for territorial success at an ambient temperature of either 18 or $27^{\circ} \mathrm{C}$

\begin{tabular}{ccc}
\hline \multirow{2}{*}{$\begin{array}{c}\text { Male } \\
\text { developmental } \\
\text { temperature }\end{array}$} & $\begin{array}{c}\text { Mean territorial score at different } \\
\text { test temperatures }\end{array}$ \\
\cline { 2 - 3 } & $18^{\circ} \mathrm{C}(N=34)$ & $27^{\circ} \mathrm{C}(N=38)$ \\
\hline $18^{\circ} \mathrm{C}$ & $1.9 \pm 0.30$ & $2.3 \pm 0.36$ \\
$25^{\circ} \mathrm{C}$ & $3.6 \pm 0.41$ & $6.6 \pm 0.52$ \\
& $\left(P=0.007^{*}\right)$ & $\left(P<0.001^{*}\right)$ \\
\hline
\end{tabular}

$N$ is the number of pairs in each sample.

${ }^{*} P$-values are two-tailed tests (Wilcoxon matched-pairs signed-ranks tests) of the probability that males with different developmental temperatures have equivalent territorial scores. By using this paired test, we circumvent the non-independence of territorial scores of individual males.

effects by comparing numerical territorial scores number of censuses at which a male alone occupied the food/oviposition site) of the two males in each paired contest. Males raised at $25^{\circ} \mathrm{C}$ had significantly higher scores than did males raised at $18^{\circ} \mathrm{C}$ at both test temperatures (Table I; Wilcoxon matched-pairs signed-ranks tests: $P=0.007$ at $18^{\circ} \mathrm{C}, P<0.001$ at $27^{\circ} \mathrm{C}$ ).

We next checked the frequency of territorial success (categorical scale) of males from the two developmental temperatures. The larger of the competing males was infrequently the more successful male (only 19 of 53 trials, 36\%). When tested at high ambient temperature $\left(27^{\circ} \mathrm{C}\right)$, males raised at high temperature were almost always $(85 \%, N=27)$ more likely to be classified as winners than were males raised at low temperature $(P<0.001)$. When tested at low temperature, males raised at high temperature were again almost always more successful $(81 \%, N=26, P<0.001)$. Based on categorical scores, the advantage of males raised at high temperatures was not significantly ( $\chi^{2}$ test: $\left.P=0.67\right)$ greater at high than at low test temperatures.

The above analyses compare territorial success of males raised at different temperatures, but do not simultaneously consider possible effécts of (or interactions between) test temperature or differences in dry body mass. However, a general linear model (Methods) with all these effects indicates that the only significant term was the intercept. In other words, males raised at $25^{\circ} \mathrm{C}$ had relatively high territorial success $(P<0.001)$ that was independent of test temperature $(P=0 \cdot 145)$, of the difference in mass between tested individuals $(P=0.947)$ and of the interaction between test temperature and the difference in mass $(P=0.566)$.

\section{Parental Temperature and Territorial Success}

We conducted a small-scale test ( $N=16$ pairs) to determine whether parental temperature regime might influence the territorial success of their male offspring (at $27^{\circ} \mathrm{C}$ ), where all tested males were raised only at $25^{\circ} \mathrm{C}$. Indeed, males whose parents were raised at $25^{\circ} \mathrm{C}$ had significantly higher territorial scores $(6.5 \pm 0.058)$ than did males whose parents were raised at $18^{\circ} \mathrm{C}(3.8 \pm 0.62$; Wilcoxon matched-pairs signed-ranks test: twotailed $P=0.046$ ).

\section{DISCUSSION}

Our experiments demonstrate that males raised at $25^{\circ} \mathrm{C}$ were successful in paired territorial contests with males raised at $18^{\circ} \mathrm{C}(P<0 \cdot 001)$. This pattern was independent of test temperature $\left(18\right.$ or $27^{\circ} \mathrm{C}$, $P=0.145$ ), of the difference in body mass of the individuals being tested $(P=0.947)$, or of the interaction of these variables $(P=0.566)$. As argued below, these patterns contradict both the size-advantage hypothesis and the acclimationadvantage hypothesis.

The 'size-advantage hypothesis' predicted that low-temperature males, by virtue of their larger size, would be successful in territorial contests at both high and low ambient temperature. In our experiments, however, low-temperature males were infrequently successful and had relatively low territorial scores at either temperature (Table I). Clearly, bigger isn't always better, contrary to the impression given by the literature (see references in Introduction). Consequently, whether large size is or is not associated with male territorial success may depend on the particular developmental and genetic factors responsible for large adult size. For example, large males may well be successful if their large size reflects development under uncrowded conditions (Hoffmann 1987b), but not if it reflects development at low temperature (herein). (This pattern suggests that the large-size advantage documented in field studies 
(Partridge et al. 1987; Markow 1988; Santos 1988) may be due to something other than developmental temperature (L. Partridge, personal communication). Interestingly, a recent analysis (Thomas 1993) suggests that within-season variation in body size in $D$. buzzatii is determined primarily by variation in nutrition not in developmental temperature.) Moreover, following selection for male territorial success, selected males had enhanced aggression and territorial success but were not larger in size (Hoffmann 1988). Thus, size per se may be a 'red herring' with respect to territorial success.

The acclimation-advantage hypothesis (Leroi et al. 1994; Huey et al. 1995) predicted that (1) males raised at high temperature would win contests at high ambient temperature, which they did and (2) that they would lose at low temperature, which they did not. Thus, development in a particular environment does not guarantee enhanced performance (or at least territorial success) in that same environment. However, the territorial advantage of males raised at $25^{\circ} \mathrm{C}$ was slightly but not significantly $(P=0.145)$ reduced in contests at $18^{\circ} \mathrm{C}$ relative to those at $27^{\circ} \mathrm{C}$ (see Table I). It would be interesting to determine whether development at $25^{\circ} \mathrm{C}$ might become a disadvantage at test temperatures lower than $18^{\circ} \mathrm{C}$, consistent with the acclimation-advantage hypothesis.

The observed patterns can be interpreted in two ways. First, smaller might be better with regard to male territoriality. After all, $25^{\circ} \mathrm{C}$ males, which were generally small, did have relatively high territorial success at both test temperatures. However, this suggestion is strongly contraindicated by many laboratory and field studies (references above) with Drosophila. More to the point, the difference in mass between paired males had no effect on territorial success $(P=0 \cdot 947)$. Second, development at $25^{\circ} \mathrm{C}$ might be physiologically advantageous relative to development at $18^{\circ} \mathrm{C}$ (Cohet \& David 1978; Huey et al. 1995), such that . males raised at $25^{\circ} \mathrm{C}$, though small in size, might be sufficiently vigorous to more than compensate for being small. By extension, perhaps an 'optimal' developmental temperature exists for flies (Cohet \& David 1978: Huey et al. 1995), such that flies raised at their optimal temperature might have relatively high fitness independent of the environment they experience as adults. This optimal developmental temperature hypothesis is potentially testable by comparing dominance of males raised at a series of temperatures, not just at two. Especially interesting will be the relative territoriality of males raised at very high temperature $\left(\mathrm{ca} 29^{\circ} \mathrm{C}\right.$ ). These males will be smaller than males raised at $25^{\circ} \mathrm{C}$ (David et al. 1983). If smaller is better, males raised at $29^{\circ} \mathrm{C}$ should have high territorial success at 18,25 , or $29^{\circ} \mathrm{C}$. If, however, $25^{\circ} \mathrm{C}$ represents an optimal developmental temperature (Cohet \& David 1978; Huey et al. 1995), then male flies raised at $25^{\circ} \mathrm{C}$ should have greater territorial success than those raised at $29^{\circ} \mathrm{C}$ (or $18^{\circ} \mathrm{C}$ ) at all three test temperatures.

A variety of independent data support the suggestion that development of $D$. melanogaster at $21-25^{\circ} \mathrm{C}$ may be physiologically advantageous relative to development at lower or higher temperature (Cohet \& David 1978). Flies raised at $25^{\circ} \mathrm{C}$ have much higher maze-running success than do flies raised at $13^{\circ} \mathrm{C}$ (Cohet 1974). Males raised at $25^{\circ} \mathrm{C}$ run faster at a variety of temperatures than do males raised at $18^{\circ} \mathrm{C}$ (Gilchrist 1993). Furthermore, females raised at 21 or $25^{\circ} \mathrm{C}$ had greater maximal daily egg production as well as higher lifetime egg production than did flies raised at lower $\left(\leq 17^{\circ} \mathrm{C}\right)$ or higher $\left(\geq 28^{\circ} \mathrm{C}\right)$ temperatures, when tested at $25^{\circ} \mathrm{C}$ (Cohet \& David 1978). However, the thermal sensitivity of similar traits was less pronounced in two parallel studies (McKenzie 1978).

Our cross-generational experiment was small scale, but it nevertheless suggests that males whose parents are raised at $25^{\circ} \mathrm{C}$ had greater territorial success than did males whose parents are raised at $18^{\circ} \mathrm{C}$, at least when tested at $27^{\circ} \mathrm{C}$. Cross-generational effects of temperature are also known for adult dry mass and heat tolerance (Crill 1991) and fecundity in D. melanogaster (Huey et al. 1995), and now for territorial success as well. Cross-generational effects of many other factors have been documented in insects (Mousseau \& Dingle 1991).

The above patterns generally suggest that flies raised at $25^{\circ} \mathrm{C}$ (and whose parents are raised at $25^{\circ} \mathrm{C}$ ) are more vigorous as adults than are flies raised at $18^{\circ} \mathrm{C}$ (or whose parents are raised at $18^{\circ} \mathrm{C}$ ). Interestingly, female D. melanogaster preferentially lay their eggs at $23-25^{\circ} \mathrm{C}$ in a laboratory thermal gradient (Fogleman 1979). If selection has favoured females that select oviposition sites with physiologically suitable temperatures (in other words, 'mother knows best'), then these behavioural results are also consistent 
with the idea that an optimal developmental (parental) temperature exists and is near $25^{\circ} \mathrm{C}$. One possible exception is, however, an experiment in which males raised at $18^{\circ} \mathrm{C}$ had faster mating speeds than did males raised at $26^{\circ} \mathrm{C}$ (Ewing 1964). However, these experiments were noncompetitive. Moreover, experiments involving artificial selection for male territorial success suggest that mating speed has limited relevance to mating success (Hoffmann 1988): relative to control males, the selected males had enhanced territorial success and enhanced mating success but nevertheless had similar mating speeds (Hoffmann 1988). Thus mating speed may be weakly related to mating success when territories are present.

We raise three caveats concerning our interpretations. First, our results might be dependent on the particular stocks we used, given that these flies had been evolving at $25^{\circ} \mathrm{C}$ for over 7 years. Indeed, these flies are known to differ in the thermal sensitivity of development time from lines evolving for the same period at $16.5^{\circ} \mathrm{C}$ (Huey et al. 1991). However, testing a California stock of D. melanogaster that had been at $25^{\circ} \mathrm{C}$ for less than 1 year, Gilchrist (1993) found that male flies raised at $25^{\circ} \mathrm{C}$ also ran faster than flies raised at $18^{\circ} \mathrm{C}$. This, plus evidence from a variety of other stocks (above), suggest that the differences we observed are robust. Of course, this issue must ultimately be resolved either by testing flies that were more recently collected from nature, or by testing flies that have been evolving for several years at different temperatures (e.g. Cavicchi et al. 1985; Huey et al. 1991).

Second, although we have interpreted our findings in terms of the effects of developmental temperature on the physiological vigour and the size of adults, we recognize that developmental temperatures may influence male territorial success in ways that are independent of physiological vigour or body size. For example, developmental temperatures influence mating success in some Drosophila via effects on epicuticular hydrocarbons (Markow \& Toolson 1990). Conceivably, those hydrocarbons might influence male territorial success as well.

Third, results of previous stydies (see references in Introduction) suggest that males raised at $25^{\circ} \mathrm{C}$ will not only have high territorial success, but also high reproductive success relative to males raised at $18^{\circ} \mathrm{C}$. However, this hypothesis should be tested directly in separate experiments.
The concept of an optimal developmental temperature (Cohet \& David 1978; Huey et al. 1995), and perhaps even that of an optimal parental temperature, has significant applied implications. If the physiological and behavioural vigour of an adult insect ('quality control', Boller \& Chambers 1977) is strongly influenced by developmental and parental temperatures, then the impact of insect-release programmes (e.g. sterile male, biocontrol) may be enhanced by raising insects at temperatures that maximize offspring performance and vigour.

In conclusion, developmental and parental temperatures have profound effects on male territorial success in D. melanogaster. The developmental effect is independent both of the temperature at which territorial success is tested and also of difference in body size between males. Consequently, studies attempting to address the impact of body size on fitness may be clarified by recognizing that mapping of size on fitness may not be simple: whether large size confers an advantage may depend strongly on the particular developmental and genetic factors that are responsible for large size.

\section{ACKNOWLEDGMENTS}

We thank L. Partridge for flies used in these experiments, L. Partridge and A. Hoffmann for helpful suggestions during planning, $\mathrm{K}$. Ward for helping conduct the experiments, and C. Boake, A. Hoffmann, R. Jaeger, T. Markow, L. Partridge and two anonymous referees for constructive discussions and suggestions. C. Janson helped derive the general linear model used in our analysis. Research funded by NSF BSR-8919600, DEB9301151 (analysis phase only), and an NSF Predoctoral Fellowship to K.Z.

\section{REFERENCES}

Atkinson, W. D. \& Shorrocks, B. 1977. Breeding site specificity in the domestic species of Drosophila. Oecologia (Berl.), 20, 223-233.

Barbault, R. 1988. Body size, ecological constraints, and the evolution of life-history strategies. In: Evolutionary Biology (Ed. by M. K. Hecht, B. Wallace \& G. T. Prance), pp. 261-286. New York: Plenum Press.

Boake, C. R. B. 1989. Correlations between courtship success, aggressive success, and body size in a picturewinged fly, Drosophila silvestris. Ethology, 80, 318329. 
Boller, E, F. \& Chambers, D. L. (Eds) 1977. Quality Control: an Idea Book for Fruit Fly Workers. WPRS Bulletin 1977/5. International Organization for Biological Control of Noxious Animals and Plants.

Cavicchi, S., Guerra, D., Giorgi, G. \& Pezzoli, C. 1985. Temperature-related divergence in experimental populations of Drosophila melanogaster. I. Genetic and developmental basis of wing size and shape variation. Genetics, 109, 665-689.

Cohet, Y. 1974. Réduction de l'activité locomotrice d'adultes de Drosophila melanogaster provoquée par développement à basse température. Rev. comp. Anim., 8, 121-125.

Cohet, Y. \& David, J. 1978. Control of the adult reproductive potential by preimaginal thermal conditions. Oecologia (Berl.), 36, 295-306

Crill, W. D. 1991. High parental and developmental temperatures increase heat resistance in adult Drosophila melanogaster. Am. Zool, , 31, 58.

David, J. R., Allemand, R., Van Herrewege, J. \& Cohet, Y. 1983. Ecophysiology: abiotic factors. In: The Genetics and Biology of Drosophila (Ed. by $\mathrm{M}$. Ashburner, H. L. Carson \& J. N. Thompson), pp. 106-109. London: Academic Press.

Dow, M. A. \& von Schilcher, F. 1975. Aggression and mating success in Drosophila melanogaster. Nature, Lond, 254, 511-512.

Ewing, A. A. 1964. The influence of wing area on the courtship behaviour of Drosophila melanogaster. Anim. Behav., 12, 316-320.

Fogleman, J, C. 1979. Oviposition site preference for substrate temperature in Drosophila melanogaster. Behav. Genet., 9, 407-412.

Gilchrist, G. W. 1993. Specialists and generalists in variable environments. Ph.D. thesis, University of Washington, Seattle.

Hillesheim, E. \& Stearns, S. C. 1991. The responses of Drosophila melanogaster to artificial selection on body weight and its phenotypic plasticity in two larval food environments. Evolution, 45, 1909-1923.

Hofmann, A. A. 1987a. A laboratory study of male territoriality in the sibling species Drosophila melanogaster and D. simulans. Anim. Behav., 35, $807-818$

Hoffmann, A. A. 1987b. Territorial encounters between Drosophila males of different sizes. Anim. Behav., 35, 1899-1901

Hoffmann, A. A. 1988. Heritable variation for territorial success in two Drosophila melanogaster populations. Anim. Behav., 36, 1180-1198.

Hoffmann, A. A. 1990. The influence of age and experience with conspecifics on territorial behavior in Drosophila melanogaster. J. Insect Behav., 3, 1-12.

Hoffmann, A. A. \& Cacoyianni, Z. 1990. Territoriality in Drosophila melanogaster as a conditional strategy. Anim. Behav., 49, 526-537.

Huey, R. B., Partridge, L. \& Fowler, K. 1991. Thermal sensitivity of Drosophila melanogaster responds rapidly to laboratory natural selection. Evolution, $\mathbf{4 5}$, $751-756$

Huey, R. B., Wakefield, T., Crill, W. D. \& Gilchrist, G. W. 1995. Within- and between-generation effects of temperature on early fecundity of Drosophila melanogaster. Heredity, 74, 216-223.

Jones, J. S., Coyne, J. A. \& Partridge, L. 1987. Estimation of the thermal niche of Drosophila melanogaster using a temperature-sensitive mutation. Am. Nat., 120, 83-90.

Leroi, A. M., Bennett, A. F. \& Lenski, R. E. 1994. Temperature acclimation and competitive fitness: an experimental test of the beneficial acclimation assumption. Proc. natn. Acad. Sci. U.S.A., 91, 1917 1921.

Long, C. E., Markow, T. A. \& Yaeger, P. 1980. Relative male age, fertility, and competitive mating success in Drosophila melanogaster. Behav. Genet, 10, 163-170.

McKenzie, J. A. 1978. The effect of developmental temperature on population flexibility in Drosophila melanogaster and D. simulans. Austral. J. Zool., 26, $105-112$.

Markow, T. A. 1988. Reproductive behavior of Drosophila melanogaster and D. nigrospiracula in the field and in the laboratory, J. comp. Psychol., 102, $169-173$

Markow, T. A. \& Sawka, S. 1992. Dynamics of mating success in experimental groups of Drosophila melanogaster (Diptera: Drosophilidae). J. Insect Behav., 5, 375-383.

Markow, T. A. \& Toolson, E. C. 1990. Temperature effects on epicuticular hydrocarbons and sexual isolation in Drosophila mojavensis. In: Ecological and Evolutionary Genetics of Drosophila (Ed. by J. S. F. Barker, W. T. Starmer \& R. J. Macintyre), pp. 315-331. New York: Plenum Press.

Mousseau, T. A. \& Dingle, H. 1991. Maternal effects in insect life histories. A. Rev. Entomol., 36, 511-534.

Partridge, L, \& Farquhar, M. 1983. Lifetime mating success of male fruitflies (Drosophila melanogaster) is related to their size. Anim. Behav., 31, 871-877.

Partridge, L., Hoffmann, A. \& Jones, J. S. 1987. Male size and mating success in Drosophila melanogaster and D. pseudoobscura under field conditions. Anim. Behav., 35, 468-476.

Robertson, F. W. 1963. The ecological genetics of growth in Drosophila. 6. The genetic correlation between the duration of the larval period and body size in relation to larval diet. Genet. Res., 4, 7492.

Roff, D. 1981. On being the right size. Am. Nat., 118, $405-422$

Santos, M.. Ruiz, A., Barbadilla, A., Quezada-Diaz, J. E., Hasson, E. \& Fontdevila, A. 1988. The evolutionary history of Drosophila. XIV. Larger flies mate more often in nature. Heredity, 61, 255-262.

Scheiner. S. M. \& Lyman, R. F. 1989. The genetics of phenotypic plasticity. I. Heritability. J. evol. Biol., 2, 95-107.

Taylor, F. 1981. Ecology and evolution of physiological time in insects. Am. Nat., 117, 1-23.

Thomas, R. H. 1993. Ecology of body size in Drosophila buzzatii: untangling the effects of temperature and nutrition. Ecol. Entomol., 18, 84-90.

Wilkinson, G. S. 1987. Equilibrium analysis of sexual selection on Drosophila melanogaster. Evolution, 41, 11-21. 